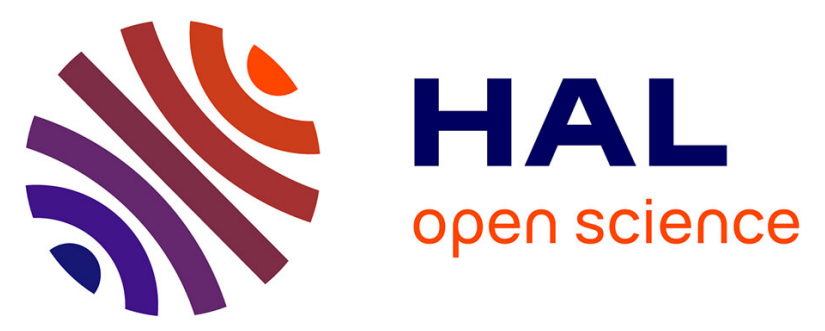

\title{
Association between prenatal exposure to traffic-related air pollution and preterm birth in the PELAGIE mother-child cohort, Brittany, France. Does the urban-rural context matter?
}

Mélanie Bertin, Cécile Chevrier, Tania Serrano, Christine Monfort, Florence Rouget, Sylvaine Cordier, Jean-François Viel

\section{To cite this version:}

Mélanie Bertin, Cécile Chevrier, Tania Serrano, Christine Monfort, Florence Rouget, et al.. Association between prenatal exposure to traffic-related air pollution and preterm birth in the PELAGIE mother-child cohort, Brittany, France. Does the urban-rural context matter?. Environmental Research, 2015, 142, pp.17-24. 10.1016/j.envres.2015.06.005 . hal-01165108

HAL Id: hal-01165108

https://hal-univ-rennes1.archives-ouvertes.fr/hal-01165108

Submitted on 23 Sep 2015

HAL is a multi-disciplinary open access archive for the deposit and dissemination of scientific research documents, whether they are published or not. The documents may come from teaching and research institutions in France or abroad, or from public or private research centers.
L'archive ouverte pluridisciplinaire HAL, est destinée au dépôt et à la diffusion de documents scientifiques de niveau recherche, publiés ou non, émanant des établissements d'enseignement et de recherche français ou étrangers, des laboratoires publics ou privés. 
Association between prenatal exposure to traffic-related air pollution and preterm birth in the PELAGIE mother-child cohort, Brittany, France. Does the urban-rural context matter?

Mélanie Bertin ${ }^{1,2,3}$, Cécile Chevrier ${ }^{1,2}$, Tania Serrano ${ }^{1,2,3}$, Christine Monfort, ${ }^{1,2}$ Florence Rouget $^{1,2,4}$, Sylvaine Cordier, ${ }^{1,2}$ Jean-François Viel ${ }^{1,2,5, *}$

${ }^{1}$ INSERM U1085-IRSET, avenue Professeur Léon Bernard, 35043 Rennes, France.

${ }^{2}$ University of Rennes 1, Rennes, France.

${ }^{3}$ EHESP School of Public Health, Sorbonne Paris Cité, Rennes, France.

${ }^{4}$ Department of Pediatrics, University Hospital, Rennes, France

${ }^{5}$ Department of Epidemiology and Public Health, University Hospital, Rennes, France

* Corresponding author:

Jean-François VIEL

INSERM-IRSET, Department of Epidemiology and Public Health, University Hospital 2 rue Henri Le Guilloux, 35033 Rennes, France.

E-mail: jean-francois.viel@univ-rennes1.fr

Fax: +33299289766 


\section{Funding}

This work was supported by a grant from the French Institute for Public Health Research (IReSP), contract $\mathrm{n}^{\circ}$ AMC11004NSA-DGS and a PhD grant from the French School of Public Health (EHESP).

\section{Competing financial interests}

The authors have no competing financial interests to declare

\section{Human subjects research approval}

This study used information collected through the mother child PELAGIE cohort, and all participants provided informed consent. The appropriate national ethics committees approved the constitution of the cohort.

\section{Disclosure statement}

The authors report they have no conflicts of interest or financial relationships to disclose. 


\begin{abstract}
Introduction: Evidence has accumulated that exposure to ambient air pollution during pregnancy may influence preterm birth (PTB) in urban settings. Conversely, this relation has barely been investigated in rural areas where individual characteristics (demographic, socioeconomic, and psychosocial factors) and environmental co-exposures may differ.
\end{abstract}

Objective: We examined the association between prenatal exposure to traffic-related air pollution and PTB among pregnant women from the PELAGIE mother-child cohort (Brittany, France, 2002-2006) living in urban $(\mathrm{n}=1550)$ and rural $(\mathrm{n}=959)$ settings.

Methods: Women's residences were classified as either urban or rural according to the French census bureau rural-urban definitions. Nitrogen dioxide $\left(\mathrm{NO}_{2}\right)$ concentrations at home addresses were estimated from adjusted land-use regression models as a marker of traffic-related pollution. Associations between $\mathrm{NO}_{2}$ concentrations and PTB were assessed with logistic regression models.

Results: Prevalence of PTB was similar among women living in urban (3.2\%) and in rural (3.5\%) settings. More positive socioeconomic characteristics and health behaviors but more single-parent families were observed among urban women. $\mathrm{NO}_{2}$ exposure averaged $20.8 \pm 6.6$ $\mu \mathrm{g} . \mathrm{m}^{-3}$ for women residing in urban areas and $18.8 \pm 5.6 \mu \mathrm{g} \cdot \mathrm{m}^{-3}$ for their rural counterparts. A statistically significant increased risk of PTB was observed among women exposed to $\mathrm{NO}_{2}$ concentrations $\geq 16.4 \mu \mathrm{g} . \mathrm{m}^{-3}$ and residing in urban areas but not among their rural counterparts.

Discussion: The results of this study, conducted in a region with interspersed urban-rural areas, are in line with previous findings suggesting an increased risk of PTB associated with higher $\mathrm{NO}_{2}$ concentrations for women living in urban areas. The absence of association among their rural counterparts for whom exposure levels were similar suggests that environmental mixtures and psychosocial inequalities might play a role in this heterogeneity.

$\underline{\text { Keywords: }}$ Preterm birth, nitrogen dioxide, traffic-related air pollution, urban-rural context 


\section{Introduction}

Preterm birth (PTB) has been identified as an important public health issue due to its major contribution to mortality rates during both the perinatal and early neonatal periods ${ }^{1}$. PTB has also been associated with notable lifelong health consequences ${ }^{2,3}$ including increased risks of adulthood morbidity ${ }^{1}$. The World Health Organization has recently estimated that worldwide 15 million babies are born preterm each year ${ }^{4}$, with prevalence rates in 184 countries ranging from $5 \%$ to $18 \%$. Their apparent increase, including in developed countries, is a cause of concern. In France, this prevalence was estimated at $6.6 \%$ in 2010 (versus $6.3 \%$ in 2003) for an estimated $55000 \mathrm{PTBs}^{5}$. Although some portion of this increase may be attributed to technological advances in neonatal care, maternal risk factors including pregnancy at later ages and environmental and social factors are also suggested as potential contributors ${ }^{6-10}$.

Ambient air pollution has been identified as a potential risk factor for PTB $^{11}$. Although results vary substantially between epidemiological studies ${ }^{11}$, the underlying biological mechanisms are likely to be complex and multiple, given the chemical and physical heterogeneity of air pollutants and the various stages of fetal vulnerability during pregnancy ${ }^{12}$. Researchers have however highlighted two principal mechanisms that induce either systemic inflammation or oxidative stress, or both ${ }^{13}$. The first potential biological mechanism involves an inflammatory cascade (with proinflammatory cytokines and prostaglandin detected in the placenta, choriodecidual space, amniotic fluid, and fetal blood) that has been associated with preterm labor, with or without preterm premature rupture of membranes ${ }^{13,14}$. Conjointly, maternal inflammation may increase her susceptibility to both systemic and genital tract infection, which is also considered a direct explanation of $\mathrm{PTB}^{13}$. The second mechanism includes an oxidative stress pathway that may activate or reinforce this inflammatory mechanism. The reactive oxygen species produced may also directly target amniotic and chorionic membranes, leading either to their preterm premature rupture ${ }^{14}$ or to endothelial and angiogenic dysfunction of the placenta ${ }^{15}$. These modifications also play a central role in the pathogenesis of preeclampsia ${ }^{16,17}$ and gestational hypertension ${ }^{18}$, each associated with both spontaneous and medically induced preterm delivery ${ }^{7}$ 
Most studies investigating the impact of air pollution on PTB have been conducted in urban areas, although rural areas are characterized by different levels and different mixtures of air pollutants. Population characteristics, including health behaviors (diet, smoking status), socioeconomic (occupation, educational level) and psychosocial factors (stress, social support), and environmental and social characteristics of places (neighborhood deprivation, health care access, traffic noise, natural spaces) may also vary along the urban-rural continuum and increase confounding or mediate bias ${ }^{19,20}$. Furthermore, a growing body of evidence indicates that living near green spaces may improve birth outcomes ${ }^{9,21-26}$ and more specifically decrease the risk of $\mathrm{PTB}^{24}$. Although green spaces may reduce harmful environmental exposures to air pollutants and traffic noise, for example, the association of PTB with either residential greenness or other road traffic nuisance, also appears to be independent of air pollution exposure ${ }^{24,27}$. Socially disadvantaged areas, suggested to have higher burdens of pollution exposure ${ }^{28,29}$, have also been associated with increased risk of $\mathrm{PTB}^{6,8}$. Accordingly, these physical and social environmental factors must be considered, like individual characteristics, to be potential confounders of the relation between air pollution and PTB.

In this study we examine the association between prenatal exposure to traffic-related air pollution and the risk of PTB, and we assess whether place of residence during pregnancy (urban or rural area) modifies this association in the PELAGIE mother-child cohort.

\section{Methods}

\subsection{Study population}

The PELAGIE cohort included 3421 pregnant women living in the Brittany region (France) from 2002 to 2006. They were recruited during prenatal care visits to gynecologists, obstetricians, or ultrasonographers before the $19^{\text {th }}$ week of gestation. They were asked to complete a selfadministered questionnaire at home concerning family, social, and demographic characteristics, diet, and lifestyle. This analysis is restricted to the 3226 women who gave birth to singleton liveborn infants without any major congenital malformation. Home address geocoding at inclusion was manually checked, and its accuracy was estimated at 15 to $250 \mathrm{~m}$. To exploit the 
fine resolution of the exposure data, we excluded women whose address could not be geocoded or who lived outside Brittany $(n=44)$ and those who reported only their town of residence ( $n=661$ ). After we excluded the 12 with missing gestational age data, we were able to consider 2509 women in this analysis.

The study was reviewed and approved by the relevant ethics committees, and all participating women gave informed written consent for themselves and their children.

\subsection{Assessment of PTB}

Gestational age at delivery (in weeks) was assessed by a midwife or obstetrician, who considered both the date of the last menstrual period and the ultrasound results during pregnancy. Discrepancies were resolved by clinical judgment. PTB was defined as birth occurring before 37 completed weeks of gestation.

\subsection{Air pollution exposure assessment}

Nitrogen dioxide $\left(\mathrm{NO}_{2}\right)$ concentrations, which are a well-recognized marker of traffic-related pollution $^{30}$, were estimated from a land-use regression model (LUR) on a 100-m grid across Western Europe for the years 2005-2007, as previously described elsewhere ${ }^{31}$.

To validate the extrapolation of the $\mathrm{NO}_{2}$ concentrations (2005-2007) to the four preceding years ( $\mathrm{n}=2061$ women with pregnancies between 2002 and 2004), we calculated a Pearson correlation coefficient between $\mathrm{NO}_{2}$ concentrations at their homes from the 100-m grid over the 2005-2007 period and the annual $\mathrm{NO}_{2}$ concentrations from two other datasets: the nationwide French $\mathrm{NO}_{2}$ concentrations at a 4- $\mathrm{km}$ grid established in $2000^{32}$ and European-wide $\mathrm{NO}_{2}$ concentrations at a $1-\mathrm{km}$ grid established in 2001 (European APMoSPHERE project) ${ }^{33}$. The latter are described in the Supplementary material (Supplement Appendix 1). In addition, data collected at 12 air monitoring sites across Brittany were available to examine annual mean $\mathrm{NO}_{2}$ concentrations and explore their temporal evolution during the 2002-2006 period (Supplement Figure1).

The high correlations between $\mathrm{NO}_{2}$ concentrations estimated from different modeling approaches and periods (Supplement Table 1) and the temporal stability of the annual mean $\mathrm{NO}_{2}$ concentrations during the 2002-2006 period at the air monitoring sites reinforced the relevance of 
the more precise $\mathrm{NO}_{2}$ concentrations estimated over the 2005-2007 period with LUR. Geocoded maternal home addresses at birth were then matched to the appropriate $100 * 100$-m grid across Brittany with ARCGIS (version 10.2).

\subsection{Definition of the urban-rural status of maternal residence}

Municipalities from Brittany were classified according to the French Census Bureau rural-urban definition. An "urban unit" is a municipality or a group of municipalities that includes a built-up area of at least 2,000 inhabitants and in which no building is farther than $200 \mathrm{~m}$ away from its nearest neighbor. Urban units are further categorized as "highly urban", "suburban", or "isolated" municipalities depending on the municipalities involved (and their populations). All other municipalities are considered rural. Due to statistical constraints, highly urban, suburban, and isolated municipalities were aggregated into a single urban category for this study.

\subsection{Covariates}

\subsubsection{Maternal characteristics}

This study considered various maternal and infant characteristics previously shown to be potential risk factors of PTB in the literature. Therefore, we initially considered as covariates: maternal education (primary or secondary school, high school diploma (passed baccalaureate examination), or under- or postgraduate diploma), single-mother families (no or yes), maternal age $(<25,25-30,30-35$, or $>35$ years), parity (nulliparous or multiparous), smoking status at enrolment (nonsmoker at inclusion, or light smoker $<10$ cigarettes/day, or heavy smoker $\geq 10$ cigarettes/day), alcohol consumption at enrolment (abstinent, occasional, $\geq 1 \mathrm{drink} /$ day), high blood pressure before/during pregnancy (no or yes), gestational diabetes (no or yes), season of conception (spring, summer, autumn, or winter) as well as usual fish intake $(<1$ per month, $\leq 1$ per week, or $\geq 2$ per week) which has previously been associated with birth outcomes in the PELAGIE cohort ${ }^{34}$, and prepregnancy body mass index (BMI) $(<18.5,18.5-<25,25-<30$, or $\geq 30$ $\left.\mathrm{kg} / \mathrm{m}^{2}\right)$ 


\subsubsection{Environmental covariates}

\section{Neighborhood deprivation}

We used a neighborhood deprivation index estimated at the census block level in France that has previously been described elsewhere ${ }^{35}$ and shown to discriminate deprived areas appropriately in both urban and rural sectors of Brittany ${ }^{36}$. This quantitative neighborhood deprivation index was then categorized into tertiles, with the highest tertile the most deprived.

\section{Green space assessment}

To determine surrounding green space, we used the TOPO database ${ }^{\circledR}$ (French National Institute of Geographic and Forest Information - IGN), which describes woods (if surface $\geq 500 \mathrm{~m}^{2}$ ), forests, moorland, and orchards (if surface $\geq 5000 \mathrm{~m}^{2}$ ). Coverage of green spaces within a $500-\mathrm{m}$ buffer around the maternal residential address was categorized in tertiles.

\section{Distance to the coast}

Distance to the coast was used as a proxy to determine surrounding blue spaces. The GEOFLA ${ }^{\circledR}$ database (IGN), which includes coastal and inland boundaries, was used to calculate the distance from the mother's residence to the coast. A binary variable was created to define whether women lived within or more than $500 \mathrm{~m}$ from the coast.

\section{Road traffic nuisance}

Distance to a major road network was used as a proxy for exposure to road traffic nuisance (other air pollutants and noise). Using the CARTO database ${ }^{\circledR}$ (IGN), we considered major roads to be the principal regional roads and highways. A binary variable indicated whether a maternal residential address was situated within or more than $200 \mathrm{~m}$ from the nearest major road.

\subsection{Statistical analysis}

Multivariate logistic regression models were carried out to examine associations between tertiles of $\mathrm{NO}_{2}$ exposure and PTB. Odds ratios (ORs) with their 95\% confidence intervals (CIs) were estimated. P-values for linear trends across exposure tertiles were calculated coding the different categories as 1, 2, or 3. Potential confounding factors (maternal and environmental covariates, as described above) were introduced in the multivariate models if they were associated with PTB 
risk in bivariate models ( $p$-value $<0.20$ based on Fisher's exact test) (Table 1). Analyses stratified for urban-rural status or including interaction terms were also conducted to determine how associations between $\mathrm{NO}_{2}$ exposure and PTB risk were modified according to this status.

We also conducted sensitivity analyses excluding women with high blood pressure, for it might be part of a physiological pathway through which ambient air pollution may be related to $\mathrm{PTB}^{18}$. Finally, we repeated analyses considering only those women for whom address geocoding accuracy was estimated $<100 \mathrm{~m}(\mathrm{n}=1856)$.

Statistical analyses were performed with STATA SE version 12 (College Station, TX: StataCorp LP).

\section{Results}

\subsection{Characteristics of the study population}

Table 1 summarizes the descriptive and bivariate statistics. PTB accounted for $3.3 \%$ of the births in the study population. The proportions of women with hypertension or gestational diabetes, either before or during pregnancy, were higher among women with PTB as compared to women with a term delivery $(22.9 \%$ vs $5.1 \%$, and $7.2 \%$ vs $3.5 \%$, respectively). Women with PTB were more frequently nulliparous than those who gave birth at term $(57.8 \%$ vs $43.3 \%)$. They also had a lower educational level (26.5\% vs $18.4 \%)$, and lower fish intakes (21.7\% vs $17.3 \%)$. Conversely, women with term births or PTB shared similar residential characteristics (i.e., neighborhood deprivation, surrounding green spaces, distance to the nearest road and coast).

The prevalence of PTB was similar among women residing in urban (3.2\%) and rural (3.5\%) areas (Supplement Table 2). However, compared to those in urban areas, mothers residing in rural areas had a lower educational level, were younger, more frequently overweight, and ate fish less often. They were more likely to live with a partner, to smoke, and to reside in a socioeconomically disadvantaged neighborhood, which was also further from a major road and from the coast. 


\subsection{Characteristics of $\mathrm{NO}_{2}$ exposure}

Figure 1 presents the distribution of modeled $\mathrm{NO}_{2}$ concentrations in Brittany for the year 2005 . The correlations between these concentrations and green space coverage around maternal residence, their distance to the nearest coast and road are reported in Supplement Table 3. Annual mean $\mathrm{NO}_{2}$ concentration was slightly higher in urban (mean $\pm \mathrm{SD}: 20.8 \pm 6.6 \mu \mathrm{g} \cdot \mathrm{m}^{-3}$ ) than in rural areas $\left(18.8 \pm 5.6 \mu \mathrm{g} . \mathrm{m}^{-3}\right)$ and decreased with the level of neighborhood deprivation for women in both (Figure 2). $\mathrm{NO}_{2}$ concentration also decreased for women whose homes were surrounded by more green space, for women living closer to the coast, and those further from major roads, regardless of whether their residence was urban or rural.

\subsection{Association of $\mathrm{NO}_{2}$ and PTB}

The associations between $\mathrm{NO}_{2}$ exposure levels and PTB risk are shown in Table 2. High blood pressure before/during pregnancy, gestational diabetes, maternal educational level, maternal BMI, and maternal fish consumption were introduced into the models as confounders. We found that some of these effects were modified by urban-rural status (interaction $p$-value: 0.11 ). Among women living in urban areas, the risk of PTB was higher for those exposed to the two highest tertiles of $\mathrm{NO}_{2}$ concentrations (OR (16.43 -21.18 $\left.\mu \mathrm{g} \cdot \mathrm{m}^{-3}\right): 2.46,95 \% \mathrm{CI}: 1.06-5.81$; OR (> 21.18 $\left.\mu \mathrm{g} \cdot \mathrm{m}^{-3}\right): 2.35,95 \% \mathrm{CI}: 1.02-5.42$, respectively). Conversely, no association was found for women living in rural areas. When high blood pressure was excluded from the model, trends remained similar, but the strength of the association was attenuated (Supplement Table 4). Similar observations were also found after we excluded the subjects for whom address geocoding accuracy exceeded $100 \mathrm{~m}$ (Supplement Table 5). 


\section{Discussion}

This study uses data collected in the PELAGIE mother-child cohort to examine the effect of maternal exposure to $\mathrm{NO}_{2}$ on $\mathrm{PTB}$ and investigate whether the urban/rural location of the mother's home modifies this relation. We found an increased risk of PTB associated with higher $\mathrm{NO}_{2}$ concentrations only for women living in urban areas.

To our knowledge, this is the first study exploring whether and how the urban or rural nature of a mother's home environment can modify the effect of ambient air pollution on PTB. Despite the low rate of PTB reported in this study, compared with national rates $(3.2 \% \text { vs } 6.6 \%)^{5}$, our results are consistent with several studies highlighting a positive and significant association between prenatal $\mathrm{NO}_{2}$ exposure and PTB in urban areas ${ }^{11,16,37-43}$. We are unaware of any previous study that explored the influence of $\mathrm{NO}_{2}$ exposure on PTB in rural areas and therefore lack data to assess and put into perspective these findings for women living in the rural areas of Brittany.

Pregnant women in both urban and rural areas were exposed to relatively low levels of $\mathrm{NO}_{2}$ concentrations. Very few women living in either urban $(1.3 \%, n=20)$ or rural $(0.8 \%, n=8)$ areas were exposed to $\mathrm{NO}_{2}$ concentrations exceeding the $40 \mu \mathrm{g} / \mathrm{m}^{3}$ annual mean threshold set by French and international authorities. Although a previous study has shown an increased risk of PTB at a threshold of concentration around $46 \mu \mathrm{g} \cdot \mathrm{m}^{-3}\left({ }^{42}\right)$, our findings suggest that in urban areas pregnant women exposed at a lower level (around $20 \mu \mathrm{g} . \mathrm{m}^{-3}$ ) might also be at higher risk of PTB. This low concentration of $\mathrm{NO}_{2}$ has also been associated with an increased risk of PTB in two urban areas of California ${ }^{16}$.

Because women from urban and rural areas were exposed to relatively similar levels of $\mathrm{NO}_{2}$ concentrations, it is likely that other pathways or confounders may account for the greater vulnerability to traffic-related air pollution of women living in urban areas. $\mathrm{NO}_{2}$ is a precursor for a number of harmful secondary air pollutants, including nitric acid, the nitrate part of secondary inorganic aerosols $(\mathrm{PM})$ and photo oxidants (including ozone $\left.\left(\mathrm{O}_{3}\right)\right)^{44}$. The chemical compositions and concentration levels of those secondary pollutants depend on the sources and location ${ }^{45,46,13,18}$ potentially leading to different levels of toxicity and health consequences among population 
residing in urban or rural areas ${ }^{46,47,49,50}$. Moreover, social stress and psychological disorders have been specifically associated with urban environments ${ }^{51}$, and have been shown to interact with chemical exposures to exacerbate their toxic effects and increase physiological response ${ }^{52}$. Stress and proinflammatory immune reactions induced by exposure to air pollutants may have an influence on health similar to that of maternal psychological stressors ${ }^{53}$. This cumulative exposure to both urban stress and air pollution might synergistically affect maternal health and thereby increase the risk of PTB for women living in urban areas ${ }^{54}$.

The main strengths of this study come from its design and the large, diverse geographical area it covers. The PELAGIE mother-child cohort is a region-wide cohort study that collected detailed information on potential maternal socioeconomic, behavioral, and physiological risk factors at an early stage of pregnancy. The precise geocoding of the mother's home and the use of fine-scale modeled concentrations enabled us to assess $\mathrm{NO}_{2}$ exposure even for women living in remote rural areas. We also took potential individual and environmental confounders into account, including the surrounding natural space (both green and blue), neighborhood deprivation, and road traffic nuisance, all of which have previously been shown to be associated with both PTB and ambient air pollution ${ }^{8,24,27,55}$.

Some limitations must be considered in interpreting our results. $\mathrm{NO}_{2}$ concentrations were used as a marker of traffic-related air pollution exposure as in previous studies ${ }^{56,57}$. However, $\mathrm{NO}_{2}$ forms part of a complex and dynamic mixture of pollutants that itself depends on the season and the location (e.g. urban versus rural settings) ${ }^{48}$. As a result, the risk of PTB associated with air pollution could vary differentially according to the degree of urbanization because of the different pollutant mixture compositions and not because of the only $\mathrm{NO}_{2}$ concentrations. Unfortunately, fine-scale data were not available for co-pollutant exposures (e.g., ozone, secondary aerosols) over this time period to control for their potential effects. Second, we used spatial estimates of air pollutant levels generated by LUR models across the 2005-2007 periods to extrapolate $\mathrm{NO}_{2}$ concentrations at each maternal residence recruited from 2002 to 2004 . This discrepancy between measurements of $\mathrm{NO}_{2}$ concentrations and the study inclusion period may create some temporal ambiguity, although complementary analyses using different temporal sources of $\mathrm{NO}_{2}$ concentrations confirmed the stability of $\mathrm{NO}_{2}$ concentrations across Brittany during the entire study period. Because of the relatively small number of PTB cases $(n=83)$ in the study 
population, it was not possible to restrict the analyses to the women included only in 2005 and 2006 in the PELAGIE cohort ( $\mathrm{n}=455$, including 12 women with preterm offspring). Third, the annual assessment of traffic-related air pollution at women's homes in early pregnancy did not consider their possible residential and work mobility during pregnancy or any particular critical windows of exposure during the gestational period. However, contrary to birth defects, toxicological research has not yet identified any critical window for $\mathrm{PTB}^{12}$. Fourth, after adjusting for maternal characteristics to limit the potential for sociological bias, the differential impact of traffic-related air pollution on PTB remained across urban and rural settings and raises the possibility of residual confounding by psychosocial factors ${ }^{58}$. Unfortunately the PELAGIE mother-child cohort did not collect such data.

\section{Conclusion}

In this cohort study conducted in a region with interspersed urban and rural areas, we observed an increased risk of PTB associated with higher $\mathrm{NO}_{2}$ concentrations for women living in urban but not in rural areas. Although the importance of comparing different places when studying the harmful impact of air pollution is now thoroughly understood, most studies thus far have been carried out in urban areas. Beyond variations in exposure levels, differences in pollutants mixtures and chemical composition, in socioeconomic and psychosocial factors across urban and rural settings may modulate the impact of air pollution on PTB. Further studies are thus required to explore how residential and personal characteristics may modify the influence of air pollution on PTB. 


\section{Acknowledgments}

We wish to thank Kees de Hoog, Daniele Vienneau and their collaborators from the Environmental Exposures Group of the Small Area Health Statistic Unit (SAHSU) (Centre for Environment and Health, Imperial College London, King college London) for modeling and providing the European $\mathrm{NO}_{2}$ concentration data for the period 2005-2007 and for the period 2001 (European APMoSPHERE project). We also thank Antonin Mahevas from the air monitoring association in Brittany, AirBreizh, for his advice on the use of the data collected from the air monitoring sites and Helene Desqueroux and Nicolas Jeannée for providing us with the $\mathrm{NO}_{2}$ concentration data estimated at the national level by ADEME for 2001. 


\section{References}

1. Behrman RE, Butler AS. Preterm birth: causes, consequences and prevention/Commitee on Understanding Premature Birth and Assuring Healthy Outcomes, Board on Health Sciences Policy. Whashington: National Academies Press; 2007.

2. Barker DJ. The fetal and infant origins of disease. Eur J Clin Invest. 1995;25(7):457-63.

3. Barouki R, Gluckman PD, Grandjean P, Hanson M, Heindel JJ. Developmental origins of non-communicable disease: implications for research and public health. Environ Health. 2012;11:42.

4. March of Dimes, PMNCH, Save the children, WHO. Born Too Soon: The Global action report on preterm Birth. Eds CP Howson, MV Kinney, JE Lawn. World Health Organization. Geneva, 2012.

5. Blondel B, Lelong N, Kermarrec M, Goffinet F. Trends in perinatal health in France from 1995 to 2010. Results from the French National Perinatal Surveys. J Gynecol Obstet Biol la Reprod. 2012;41(4):e1-e15.

6. Metcalfe A, Lail P, Ghali WA, Sauve RS. The association between neighbourhoods and adverse birth outcomes: a systematic review and meta-analysis of multi-level studies. Paediatr Perinat Epidemiol. 2011;25(3):236-45.

7. Goldenberg RL, Culhane JF, Iams JD, Romero R. Epidemiology and causes of preterm birth. Lancet. 2008;371(9606):75-84.

8. Vos AA, Posthumus AG, Bonsel GJ, Steegers EAP, Denktaş S. Deprived neighborhoods and adverse perinatal outcome: a systematic review and meta-analysis. Acta Obstet Gynecol Scand. 2014;93(8):727-40.

9. Nieuwenhuijsen MJ, Dadvand P, Grellier J, Martinez D, Vrijheid M. Environmental risk factors of pregnancy outcomes: a summary of recent meta-analyses of epidemiological studies. Environ Health. 2013;12(1):6.

10. Romero R, Dey SK, Fisher SJ. Preterm labor: one syndrome, many causes. Science. 2014;345(6198):760-5.

11. Stieb DM, Chen L, Eshoul M, Judek S. Ambient air pollution, birth weight and preterm birth: a systematic review and meta-analysis. Environ Res. 2012;117:100-11.

12. Slama R, Darrow L, Parker J, et al. Meeting report: atmospheric pollution and human reproduction. Environ Health Perspect. 2008;116(6):791-8. 
13. Vadillo-Ortega F, Osornio-Vargas $\mathrm{A}$, Buxton $\mathrm{M}$ a, et al. Air pollution, inflammation and preterm birth: a potential mechanistic link. Med Hypotheses. 2014;82(2):219-24.

14. Dadvand P, Basagaña X, Figueras F, et al. Air pollution and preterm premature rupture of membranes: A spatiotemporal analysis. Am J Epidemiol. 2014;179(2):200-7.

15. Van den Hooven EH, Pierik FH, de Kluizenaar Y, et al. Air pollution exposure and markers of placental growth and function: the generation R study. Environ Health Perspect. 2012;120(12):1753-9.

16. Wu J, Ren C, Delfino RJ, Chung J, Wilhelm M, Ritz B. Association between local trafficgenerated air pollution and preeclampsia and preterm delivery in the South Coast Air Basin of california. Environ Health Perspect. 2009;117(11):1773-9.

17. Dadvand P, Figueras F, Basagaña $X$, et al. Ambient air pollution and preeclampsia: a spatiotemporal analysis. Environ Health Perspect. 2013;121(11-12):1365-71.

18. Pedersen M, Stayner L, Slama R, et al. Ambient air pollution and pregnancy-induced hypertensive disorders: A systematic review and meta-analysis. Hypertension. 2014;64(3):494-500.

19. Pedersen M, Siroux V, Pin I, et al. Does consideration of larger study areas yield more accurate estimates of air pollution health effects? An illustration of the bias-variance tradeoff in air pollution epidemiology. Environ Int. 2013;60:23-30.

20. Malmqvist E, Rignell-Hydbom A, Tinnerberg H, et al. Maternal exposure to air pollution and birth outcomes. Environ Health Perspect. 2011;119(4):553-8.

21. Nieuwenhuijsen MJ, Kruize H, Gidlow C, et al. Positive health effects of the natural outdoor environment in typical populations in different regions in Europe (PHENOTYPE): a study programme protocol. BMJ Open. 2014;4(4):e004951.

22. Dadvand P, de Nazelle A, Triguero-Mas M, et al. Surrounding greenness and exposure to air pollution during pregnancy: an analysis of personal monitoring data. Environ Health Perspect. 2012;120(9):1286-90.

23. Dadvand P, Sunyer J, Basagaña X, et al. Surrounding greenness and pregnancy outcomes in four Spanish birth cohorts. Environ Health Perspect. 2012;120(10):1481-7.

24. Hystad P, Davies HW, Frank L, et al. Residential greenness and birth outcomes: evaluating the influence of spatially correlated built-environment factors. Environ Health Perspect. 2008;122(10):1095-102. 
25. Markevych I, Fuertes E, Tiesler CMT, et al. Surrounding greenness and birth weight: results from the GINIplus and LISAplus birth cohorts in Munich. Health Place. 2014;26:39-46.

26. Agay-Shay K, Peled A, Crespo AV, et al. Green spaces and adverse pregnancy outcomes. Occup Environ Med. 2014:562-569.

27. Gehring U, Tamburic L, Sbihi H, Davies HW, Brauer M. Impact of noise and air pollution on pregnancy outcomes. Epidemiology. 2014;25(3):351-8.

28. Jerrett M. Global geographies of injustice in traffic-related air pollution exposure. Epidemiology. 2009;20(2):231-3.

29. Chaix B, Gustafsson S, Jerrett M, et al. Children's exposure to nitrogen dioxide in Sweden: investigating environmental injustice in an egalitarian country. J Epidemiol Community Health. 2006;60(3):234-41.

30. Morales E, Garcia-Esteban R, de la Cruz OA, et al. Intrauterine and early postnatal exposure to outdoor air pollution and lung function at preschool age. Thorax. 2015;70(1):64-73.

31. Vienneau D, de Hoogh K, Bechle MJ, et al. Western European Land Use Regression Incorporating Satellite- and Ground-Based Measurements of NO2 and PM10. Environ Sci Technol. 2013;47(23):13555-664.

32. Jeannée N, Mosqueron L, Nedellec V, et al. Évaluation de l' exposition en zones urbaines à la pollution atmosphérique : méthodes existantes et application aux PM 10 en France métropolitaine. Pollut Atmosphérique. 2006;190:197-209.

33. Beelen R, Hoek G, Pebesma E, Vienneau D, de Hoogh K, Briggs DJ. Mapping of background air pollution at a fine spatial scale across the European Union. Sci Total Environ. 2009;407(6):1852-1867. doi:10.1016/j.scitotenv.2008.11.048.

34. Guldner L, Monfort C, Rouget F, Garlantezec R, Cordier S. Maternal fish and shellfish intake and pregnancy outcomes: a prospective cohort study in Brittany, France. Environ Heal. 2007;6:33.

35. Rey G, Jougla E, Fouillet A, Hémon D. Ecological association between a deprivation index and mortality in France over the period 1997 - 2001: variations with spatial scale, degree of urbanicity, age, gender and cause of death. BMC Public Health. 2009;9:33.

36. Bertin M, Chevrier C, Pelé F, Serrano-Chavez T, Cordier S, Viel J-F. Can a deprivation index be used legitimately over both urban and rural areas? Int J Health Geogr. 2014;13:22. 
37. Maroziene L, Grazuleviciene R. Maternal exposure to low-level air pollution and pregnancy outcomes : a population-based study. Environ Heal. 2002;1:6.

38. Bobak M. Outdoor air pollution, low birth weight, and prematurity. Environ Health Perspect. 2000;108(2):173-6.

39. Leem J-H, Kaplan BM, Shim YK, et al. Exposures to air pollutants during pregnancy and preterm delivery. Environ Health Perspect. 2006;114(6):905-10.

40. Ritz B, Wilhelm M, Hoggatt KJ, Ghosh JKC. Ambient air pollution and preterm birth in the environment and pregnancy outcomes study at the University of California, Los Angeles. Am J Epidemiol. 2007;166(9):1045-52.

41. Darrow LA, Klein M, Flanders WD, et al. Ambient air pollution and preterm birth: a timeseries analysis. Epidemiology. 2009;20(5):689-98.

42. Llop S, Ballester F, Estarlich M, Esplugues A, Rebagliato M, Iñiguez C. Preterm birth and exposure to air pollutants during pregnancy. Environ Res. 2010;110:778-85.

43. Zhao Q, Liang Z, Tao S, Zhu J, Du Y. Effects of air pollution on neonatal prematurity in Guangzhou of China: a time-series study. Environ Health. 2011;10:2.

44. WHO. Health aspects of air pollution with particulate matter, ozone and nitrogen dioxide. Report on a WHO WorkingGroup. 2003. Available at: 〈http://www.euro.who.int/_data/assets/pdf_file/0005/112199/E79097.pdf (accessed 15.03.15).

45. Minguillón MC, Querol X, Baltensperger U, Prévôt ASH. Fine and coarse PM composition and sources in rural and urban sites in Switzerland: local or regional pollution? Sci Total Environ. 2012;427-428:191-202.

46. Lepers C, Billet S, Dergham M, et al. Génotoxicité comparée de particules atmosphériques PM2.5 en fonction de leur origine industrielle, urbaine ou rurale. Pollut Atmos. 2013;217.

47. Mirowsky J, Hickey C, Horton L, et al. The effect of particle size, location and season on the toxicity of urban and rural particulate matter. Inhal Toxicol. 2013;25(13):747-57.

48. WHO. Air quality guidelines for particulate matter, ozone, nitrogen dioxide and sulfur dioxide: global update 2005: Summary of risk assessment.Geneva. 2006, pp. 1-22. Available at: http://whqlibdoc.who.int/hq/2006/WHO_SDE_PHE_OEH_06.02_eng.pdf?ua1/41> (accessed 15.03.25). 
49. Steenhof M, Gosens I, Strak M, et al. In vitro toxicity of particulate matter (PM) collected at different sites in the Netherlands is associated with PM composition, size fraction and oxidative potential--the RAPTES project. Part Fibre Toxicol. 2011;8:26.

50. Sacks JD, Rappold AG, Davis JA, Richardson DB, Waller AE, Luben TJ. Influence of urbanicity and county characteristics on the association between ozone and asthma emergency department visits in North Carolina. Environ Health Perspect. 2014;122(5):506-12.

51. Lederbogen F, Kirsch P, Haddad L, et al. City living and urban upbringing affect neural social stress processing in humans. Nature. 2011;474(7352):498-501.

52. Erickson AC, Arbour L. The shared pathoetiological effects of particulate air pollution and the social environment on fetal-placental development. J Environ Public Health. 2014;2014:901017.

53. Dole N, Savitz DA, Hertz-Picciotto I, Siega-Riz AM, McMahon MJ, Buekens P. Maternal stress and preterm birth. Am J Epidemiol. 2003;157(1):14-24.

54. Wright RJ. Moving towards making social toxins mainstream in children's environmental health. Curr Opin Pediatr. 2009;21(2):222-9.

55. Llop S, Ballester F, Estarlich M, et al. Social factors associated with nitrogen dioxide (NO2) exposure during pregnancy: the INMA-Valencia project in Spain. Soc Sci Med. 2011;72(6):890-8.

56. Estarlich M, Ballester F, Aguilera I, Llop S, Freire C, Basterrechea M. Children's health residential exposure to outdoor air pollution during pregnancy and anthropometric measures at birth in a multicenter cohort in Spain. Environ Health Perspect. 2011;119(9):1333-8.

57. Brunekreef B. Health effects of air pollution observed in cohort studies in Europe. $J$ Expo Sci Environ Epidemiol. 2007;17 Suppl 2:S61-5.

58. Meng G, Thompson ME, Hall GB. Pathways of neighbourhood-level socio-economic determinants of adverse birth outcomes. Int J Health Geogr. 2013;12:32. 
Table 1: Characteristics of the study population (PELAGIE mother-child cohort, Brittany, France, 2002-2006)

\begin{tabular}{|c|c|c|c|c|c|c|c|}
\hline & \multicolumn{2}{|c|}{$\begin{array}{l}\text { Whole cohort } \\
\quad(n=2509)\end{array}$} & \multicolumn{2}{|c|}{$\begin{array}{c}\text { Term births } \\
(n=2426)\end{array}$} & \multicolumn{2}{|c|}{ PTB $(n=83)$} & \multirow[t]{2}{*}{$p$-Value ${ }^{\mathrm{a}}$} \\
\hline & $\mathbf{n}$ & $\%$ & $\mathbf{n}$ & $\%$ & $\mathbf{n}$ & $\%$ & \\
\hline \multicolumn{8}{|c|}{ Maternal and infant characteristics } \\
\hline \multicolumn{8}{|c|}{ Infant sex } \\
\hline Boy & 1268 & 50.5 & 1222 & 50.4 & 46 & 55.4 & 0.37 \\
\hline Girl & 1241 & 49.5 & 1204 & 49.6 & 37 & 44.6 & \\
\hline \multicolumn{8}{|l|}{ Maternal age, years } \\
\hline$<25$ & 270 & 10.8 & 258 & 10.6 & 12 & 14.5 & 0.69 \\
\hline $25-30$ & 986 & 39.3 & 954 & 39.3 & 32 & 38.6 & \\
\hline $30-35$ & 877 & 35.0 & 851 & 35.1 & 26 & 31.3 & \\
\hline$\geq 35$ & 376 & 15.0 & 363 & 15.0 & 13 & 15.7 & \\
\hline Multiparous & 1410 & 56.2 & 1375 & 56.7 & 35 & 42.2 & 0.01 \\
\hline \multicolumn{8}{|c|}{ High blood pressure before/during pregnancy } \\
\hline & 143 & 5.7 & 124 & 5.1 & 19 & 22.9 & $<0.01$ \\
\hline Gestational diabetes & 91 & 3.6 & 85 & 3.5 & 6 & 7.2 & 0.07 \\
\hline \multicolumn{8}{|c|}{ Maternal level of education } \\
\hline Primary/secondary school & 469 & 18.7 & 447 & 18.4 & 22 & 26.5 & 0.18 \\
\hline high school diploma & 446 & 17.8 & 433 & 17.9 & 13 & 15.7 & \\
\hline University degree & 1594 & 63.5 & 1546 & 63.7 & 48 & 57.8 & \\
\hline \multicolumn{8}{|l|}{ Fish intake } \\
\hline$<1 /$ month & 438 & 17.5 & 420 & 17.3 & 18 & 21.7 & 0.17 \\
\hline$\leq 1 /$ week & 1366 & 54.4 & 1317 & 54.3 & 49 & 59.0 & \\
\hline$\geq 2 /$ week & 705 & 28.1 & 689 & 28.4 & 16 & 19.3 & \\
\hline Single parent-family & 63 & 2.5 & 61 & 2.5 & 2 & 2.4 & 0.95 \\
\hline \multicolumn{8}{|c|}{ Maternal smoking status at enrolment } \\
\hline Nonsmoker & 2164 & 86.3 & 2094 & 86.3 & 70 & 84.3 & 0.84 \\
\hline Smoker $(<10 \mathrm{cig} / \mathrm{d})$ & 254 & 10.1 & 244 & 10.1 & 10 & 12.1 & \\
\hline Smoker $(>=10 \mathrm{cig} / \mathrm{d})$ & 91 & 3.6 & 88 & 3.6 & 3 & 3.6 & \\
\hline \multicolumn{8}{|c|}{ Maternal drinking status at enrolment } \\
\hline Abstinent & 2137 & 85.2 & 2063 & 85.0 & 74 & 89.2 & 0.58 \\
\hline Occasional ( $<1 \mathrm{drink} / \mathrm{d})$ & 323 & 12.9 & 315 & 13.0 & 8 & 9.6 & \\
\hline$>1 \mathrm{drink} / \mathrm{d}$ & 49 & 2.0 & 48 & 2.0 & 1 & 1.2 & \\
\hline \multicolumn{8}{|c|}{ Prepregnancy BMI $\left(\mathrm{kg} / \mathrm{m}^{2}\right)$} \\
\hline$<18.5$ & 1865 & 7.4 & 1811 & 74.7 & 54 & 65.1 & 0.12 \\
\hline $18.5-25$ & 458 & 74.3 & 437 & 18.0 & 21 & 25.3 & \\
\hline$>25$ & 132 & 18.3 & 129 & 5.3 & 3 & 3.6 & \\
\hline \multicolumn{8}{|l|}{ Season at early pregnancy } \\
\hline Spring & 614 & 24.5 & 598 & 24.7 & 16 & 19.3 & 0.55 \\
\hline
\end{tabular}




\begin{tabular}{|c|c|c|c|c|c|c|c|}
\hline & \multicolumn{2}{|c|}{$\begin{array}{l}\text { Whole cohort } \\
\quad(n=2509)\end{array}$} & \multicolumn{2}{|c|}{$\begin{array}{l}\text { Term births } \\
(n=2426)\end{array}$} & \multicolumn{2}{|c|}{ PTB $(n=83)$} & \multirow[t]{2}{*}{$p$-Value ${ }^{2}$} \\
\hline & n & $\%$ & $\mathbf{n}$ & $\%$ & $\mathbf{n}$ & $\%$ & \\
\hline Summer & 693 & 27.6 & 671 & 27.7 & 22 & 26.5 & \\
\hline Autumn & 563 & 22.4 & 544 & 22.4 & 19 & 22.9 & \\
\hline Winter & 639 & 25.5 & 613 & 25.3 & 26 & 31.3 & \\
\hline \multicolumn{8}{|c|}{ Socioeconomic and environmental factors } \\
\hline \multicolumn{8}{|c|}{ Neighborhood deprivation } \\
\hline Q1- Wealthiest & 810 & 32.3 & 785 & 32.4 & 25 & 30.1 & 0.73 \\
\hline Q2 & 861 & 34.3 & 829 & 34.2 & 32 & 38.6 & \\
\hline Q3- Poorest & 838 & 33.4 & 812 & 33.5 & 26 & 31.3 & \\
\hline \multicolumn{8}{|c|}{ Tertiles of surrounding green spaces (500-m buffer) } \\
\hline Q1- Lowest & 836 & 33.3 & 805 & 33.2 & 31 & 37.4 & 0.41 \\
\hline Q2 & 835 & 33.3 & 814 & 33.6 & 21 & 25.3 & \\
\hline Q3- Highest & 838 & 33.4 & 807 & 33.3 & 31 & 37.4 & \\
\hline \multicolumn{8}{|c|}{ Distance to the nearest coast } \\
\hline$>500 \mathrm{~m}$ & 2443 & 97.4 & 2361 & 97.3 & 82 & 98.8 & 0.41 \\
\hline$\leq 500 \mathrm{~m}$ & 66 & 2.6 & 65 & 2.7 & 1 & 1.2 & \\
\hline \multicolumn{8}{|c|}{ Distance to nearest major road } \\
\hline$>200 \mathrm{~m}$ & 1700 & 67.8 & 1644 & 67.8 & 56 & 67.5 & 0.96 \\
\hline$\leq 200 \mathrm{~m}$ & 809 & 32.2 & 782 & 32.2 & 27 & 32.5 & \\
\hline \multicolumn{8}{|l|}{ Type of area } \\
\hline Urban & 1550 & 61.8 & 1501 & 61.9 & 49 & 59.0 & 0.60 \\
\hline Rural & 959 & 38.2 & 925 & 38.1 & 34 & 41.0 & \\
\hline
\end{tabular}

Abbreviations: PTB, Preterm birth

${ }^{a}$ Two-sided $p$-value for differences between term births and PTB (Fisher's exact test). 
Table 2: Associations ${ }^{\mathrm{a}}$ between exposure to $\mathrm{NO}_{2}$ at maternal residence and preterm birth, for the whole cohort and stratified by the urban-rural status (PELAGIE mother-child cohort, Brittany, France, 2002-2006)

\begin{tabular}{|c|c|c|c|c|c|c|c|c|c|}
\hline \multirow{2}{*}{$\begin{array}{l}\text { Tertiles of } \mathrm{NO}_{2} \\
\text { concentration } \\
\left(\mu \mathrm{g} / \mathrm{m}^{3}\right)\end{array}$} & \multicolumn{3}{|c|}{ Whole cohort $(n=2509)$} & \multicolumn{3}{|c|}{ Urban $(n=1550)$} & \multicolumn{3}{|c|}{ Rural (n=959) } \\
\hline & OR & $95 \% \mathrm{CI}$ & $p$-value ${ }^{\mathrm{b}}$ & OR & $95 \% \mathrm{CI}$ & $p$-value ${ }^{b}$ & OR & $95 \% \mathrm{CI}$ & $p$-value ${ }^{\text {b }}$ \\
\hline$\leq 16.43$ & Ref & & 0.27 & Ref & & 0.06 & Ref & & 0.61 \\
\hline$>16.43$ to $\leq 21.18$ & 1.49 & $0.85,2.60$ & & 2.48 & $1.06,5.81$ & & 0.93 & $0.42,2.05$ & \\
\hline$>21.18$ & 1.39 & $0.79,2.45$ & & 2.35 & $1.02,5.42$ & & 0.78 & $0.30,1.99$ & \\
\hline
\end{tabular}

Abbreviations: $\mathrm{N}$, total number; $\mathrm{n}$, number of preterm birth a adjusted for high blood pressure before/during pregnancy, gestational diabetes during pregnancy, maternal educational level, maternal body mass index, and maternal fish consumption, all associated with preterm birth in the bivariate model, with a $p$-value $<0.20$.

${ }^{\mathrm{b}} p$-values are $\mathrm{p}$ for trends across tertiles of $\mathrm{NO}_{2}$ concentrations 
Figure 1: $\mathrm{NO}_{2}$ concentrations estimated in 2005 based on a land-use regression model in Brittany.

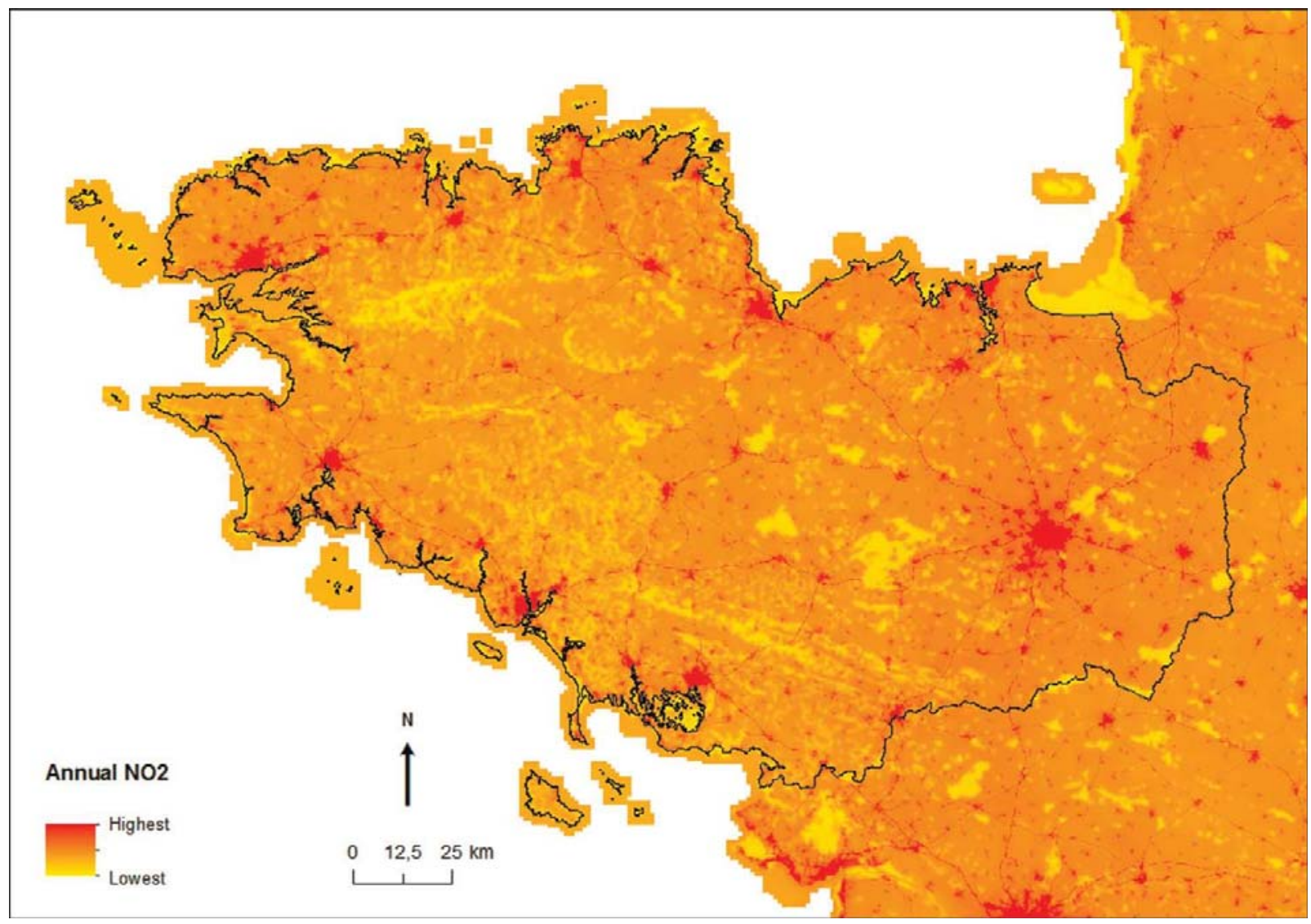


Figure 2: Mothers' prenatal exposure to $\mathrm{NO}_{2}$ concentrations according to their place of residence (urban or rural) and according to: $A$, the green space surrounding their residence (500-m buffer); B, distance from their home to the nearest coast; $C$, neighborhood deprivation tertiles; and $D$, distance from maternal home to the nearest major road (PELAGIE mother-child cohort, Brittany, France, 20002-2006).

A

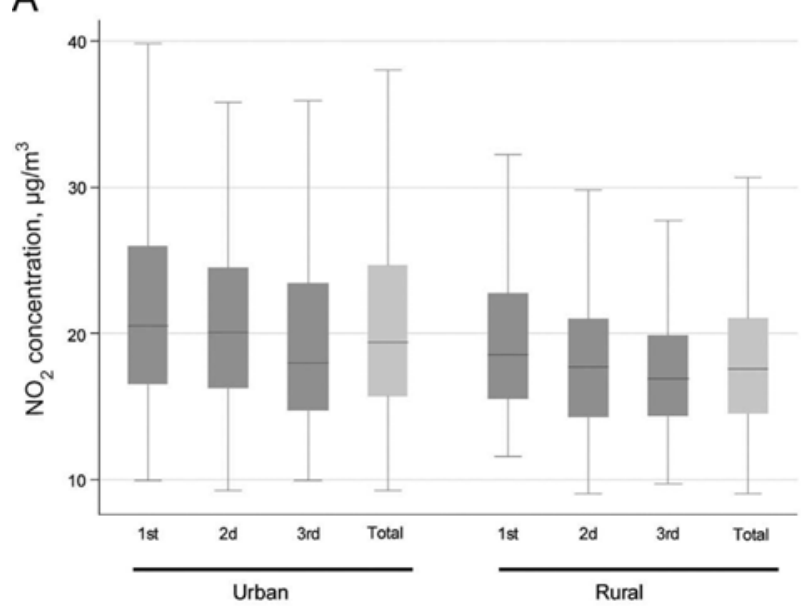

C

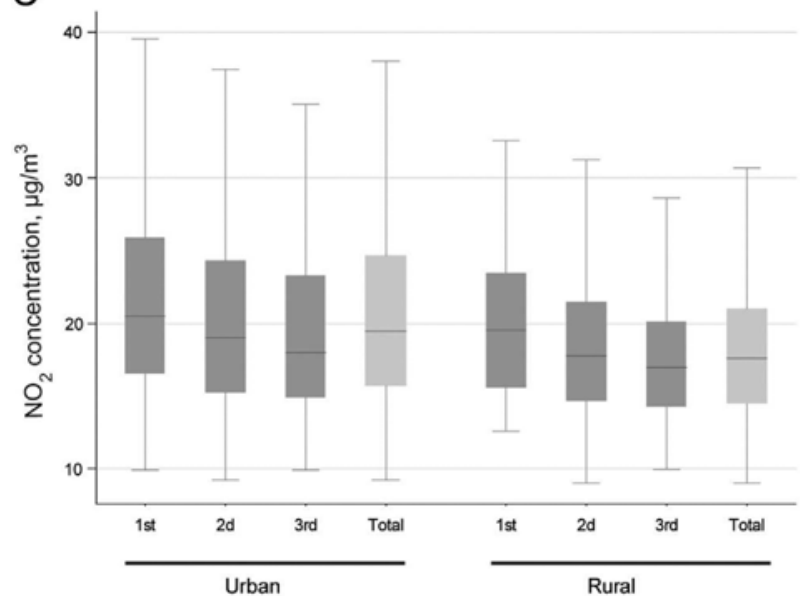

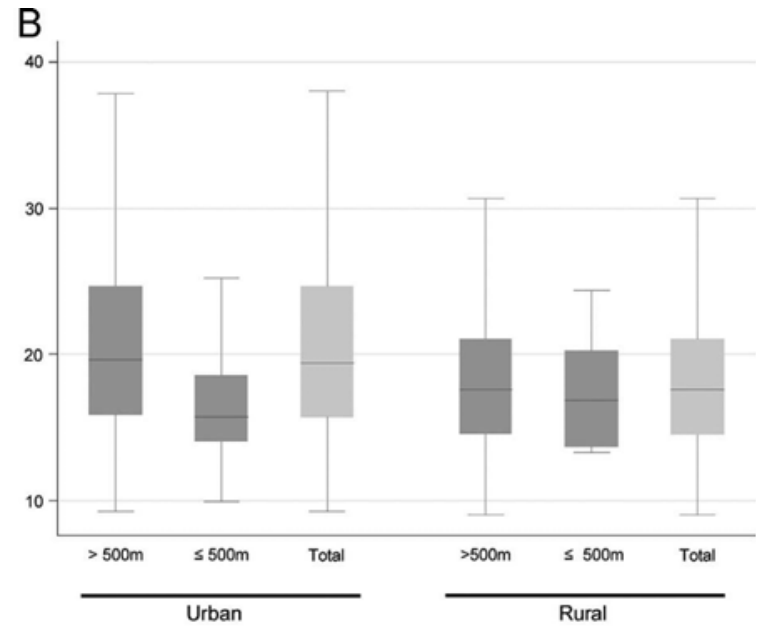

D

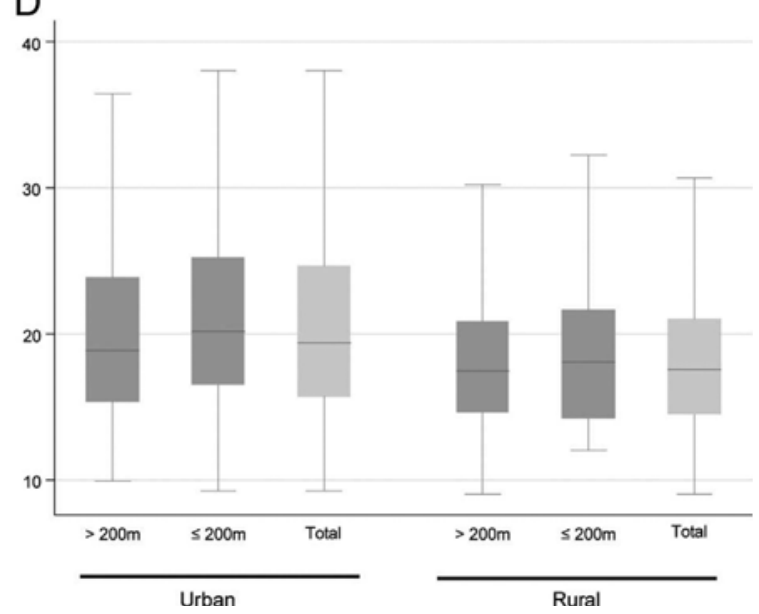

